\title{
Interpretasi Litologi Dasar Laut Pada Muara Sungai Dan Lepas Pantai Berdasarkan Analisa Shallow Seismic di Perairan Sumbawa,Nusa Tenggara Barat
}

\author{
Erna Dwi Pertiwi ${ }^{{ }^{*}}$, Sugeng Widada ${ }^{1}$, Baskoro Rochaddi ${ }^{1}$, Hariyadi $^{1}{ }^{1}$ Warsito Atmodjo ${ }^{1}$, \\ Muh Yusuf ${ }^{1}$, Azis Rifai ${ }^{1}$ \\ ${ }^{I}$ Departemen Oseanografi Fakultas Perikanan dan Ilmu Kelautan, Universitas \\ Diponegoro Jl. Prof. H.Soedarto, S.H, Tembalang Semarang, 50275 \\ Email:*dept.oseanografi.undip@gmail.com
}

\begin{abstract}
Abstrak
Sebagai bagian dari lingkungan pengendapan muara sungai dan lepas pantai Perairan Sumbawa, Nusa Tenggara Barat merupakan perairan yang mengalami proses sedimentasi dengan karakteristik fasies. Penelitian bertujuan mengetahui perbedaan tipe lapisan litologi permukaan dasar dan proses sedimentasi berdasarkan profil penampang seismik sub-bottom profiler pada muara sungai dan perairan lepas pantai di lokasi tersebut. Metode seismik sub-bottom profiler merupakan metode untuk mendapatkan gambaran sekeun sedimen. Hasil interpretasi menunjukan lapisan sedimen dasar muara sungai terdapat 7 lapisan sedimen, yaitu lapisan 1 berumur recent dengan fraksi butiran sangat halus, lapisan 2 tersusun atas fraksi butiran halus hingga sedang, lapisan 3 tersusun atas fraksi butiran sedang hingga kasar, lapisan 4 tersusun atas fraksi butiran sedang sampai dengan halus, lapisan 5 tersusun atas fraksi butiran halus sampai sedang, lapisan 6 tersusun atas fraksi butiran sangat halus, dan lapisan 7 tersusun atas lapisan sedimen keras. Pada lepas pantai ditemukan 2 lapisan dan 3 lapisan, yaitu lapisan 1 berumur recent tersusun atas fraksi sedang seperti pasir, lapisan 2 tersusun atas fraksi butiran sedang seperti pasir dan sedimen keras, dan lapisan 3 tersusun atas fraksi butiran sedang hinggahalus.
\end{abstract}

Kata kunci : sub-bottom profiler, sedimentasi, Perairan Sumbawa

\section{Abstract}

As part of the deposition of Muara and the waters off the coast of Sumbawa, West Nusa Tenggara is water that has undergone a sedimentation process with facies characteristic. The research aims to determine the different types of base lithology and sedimentation processes based on the sub-Bottom Seismic cross-section profile Profiler at the estuary of rivers and offshore waters at that location. The seismic method of the subBottom Profiler is a method for obtaining an overview of sequence sediments. Results of the interpretation indicate the base sediment layer of the river estuary there are 7 layers of sediment, namely the recent old layer 1 with a very fine grain fraction, Layer 2 consists of a fine-to-medium grain fraction, layer 3 consists of a medium fraction to coarse grain, layer 4 consists of medium to smooth fraction, layer 5 consists of fine grain fraction, and layer 7 consists of a layer of hard sediment. Off the coast found 2 layers and 3 layers,

i.e. Layer 1 has recently consisted of a moderate fraction such as sand, Layer 2 consists of medium grain fraction such as sand and hard sediment, and layer 3 consists of medium for fine shards.

Key words : Sub-bottom profiler, sedimentation, Sumbawa waters

\section{PENDAHULUAN}

Proses sedimentasi yang terjadi di muara sungai dan lepas pantai memiliki karakteristik lingkungan pengendapan yang berbeda terutama kaitannya dengan faktor oseanografi berupa kecepatan arus, pasang surut, dan gelombang serta faktor geologi berupa batuan penyusun, kondisi morfologi muara sungai dan lepas pantai. Muara sungai memiliki kecepatan arus yang sangat kecil sehingga menyebabkan kandungan sedimen tersuspensi tinggi. Sedangkan pada wilayah lepas pantai proses sedimentasinya dipengaruhi oleh kecepatan arus yang jauh lebih tinggi, kondisi morfologi yang berbeda serta proses erosi selama rentang waktu yang relatif panjang (Solihuddin et 
al., 2011). Oleh karena itu kondisi geometri dan karakteristik sedimen di muara sungai dan lepas pantai dapat dijadikan dasar interpretasi menentukan proses sedimentasi (Rahli dan Cahyono, 2019)

Hasil dari rekaman sub-bottom profiler menggunakan geolombang seismik frekuensi rendah yang merambat melalui medium air sampai permukaan dasar perairan hingga menembus setiap lapisan sedimen dapat dijadikan dasar dalam analisa sekuen sedimen sehingga dapat digunakan untuk mengintrepretasikan perbedaan proses sedimen di muara sungai dan lepas pantai. Prhantono et al., 2016 telah memanfaatkan metode ini untuk mendapatkan informasi ketebalan sedimen pada zona penambangan pasir laut untuk mengatur tahapan aktivitas penambangan pasir sehingga sumber daya pasir tidak cepat habis dan dapat meminimalisir kerusakan lingkungan.

Pada penelitian kali ini diharapkan dalam pengaplikasian manfaat shallow seismic survey di bidang kontruksi teknik seperti seperti membuat konstruksi bangunan dekat pantai dan pemasangan pipa bawah laut di Sumbawa, Nusa Tenggara Barat.

\section{MATERI DAN METODE}

\section{Materi penelitian}

Proses pengambilan data sub-bottom profiler (SBP) dan data multibeam echo sounder dilaksanakan Bersama PT. Bintang Subsea Indonesia di Perairan Sumbawa, Nusa Tenggara Barat. Survey sub-bottom profiler dilakukan sebanyak 3 lintasan setiap area penelitian yang mewakili daerah muara sungai dan perairan lepas pantai.

Luasan daerah area muara sungai $194.86 \mathrm{Ha}$ sedangkan daerah lepas pantai terdiri dari dua area yang masing-masing $430.27 \mathrm{Ha}$ dan $274.78 \mathrm{Ha}$. Panjang lintasan perekaman sub-bottom profiler muara sungai 1528.81 - 3843.85 meter. Sedangkan pada area lepas pantai adalah 1849.22 3105.40 meter dan $1948.73-2632.86$ meter. Sedangkan cross line pada masing-masing area adalah $1159.71-777.41$ meter, $935.92-$

199.52 meter, dan 963.11 - 955.07 meter. Lokasi penelitian tersebut berada di Perairan Sumbawa bagian selatan dengan batas area kajian pada koordinat 900'0"LU - 9010'0"LU dan 11700'0" BT 117050'0”BT (Gambar 1).

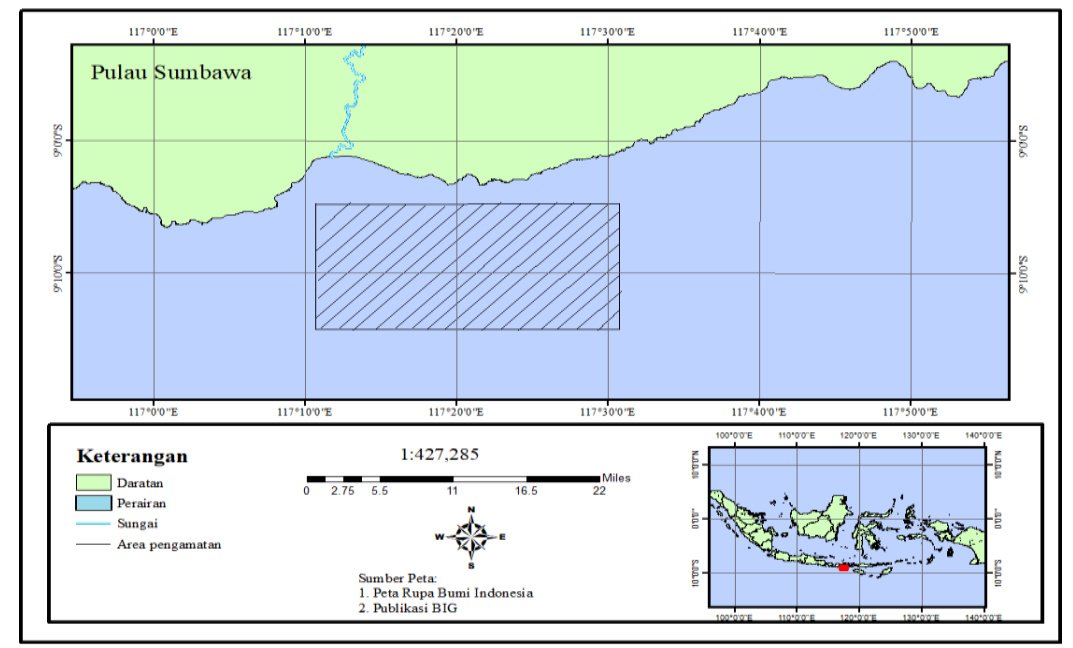

Gambar 1. Lokasi area penelitian

\section{Metode penelitian}

Penelitian ini menggunakan metode sub-bottom profiler. Dalam hal ini sumber gelombang seismic 8- $12 \mathrm{kHz}$ berupa boomer yang ditarik dengan kapal mengikuti jalur yang telah ditetapkan. Gelombang tersebut menjalar melalui media air dan menembus lapisan dasar setiap perlapisan sedimen dan pada setiap perbedaan lapisan akan dipantulkan serta diterima oleh hydrophone. Pengambilan data seabed mengunakan alat multibeam echo sounder (MBES). Data seabed digunakan sebagai pembanding data SBP dalam menggambarkan ketebalan sedimen (Isopach) dari setiap lapisan. Dalam penelitian ini pengolahan data dilakukan dengan menggunakan Coda 
Octopus:Geo Survey Engine 4.3.2 untuk pengolahan data raw SBP, Terramodel Trimbel 10.42 untuk pengolahan data pembanding antara seabed dan SBP, dan Software Surfer untuk pemodelan 3 dimensi morfologi dasar laut.

Data seabed digunakan sebagai refrensi isopach untuk mendapatkan water depth setiap reflektor di sepanjang lintasan data sub-bottom profiler di muara sungai dan lepas pantai. Untuk mendapatakan water depth reflektor maka diperlukan penjumlahan antara data seabed dan data SBP. Data seabed diperlukan juga untuk membandingkan keakuratan data digitize sub-bottom profiler dalam pemodelan 3 dimensi setiap lapisan sedimen di muara sungai dan lepas pantai.

Data mentah hasil rekaman sub-bottom profiler harus diproses lebih lanjut untuk menghilangkan noise yang ikut terekam ketika proses pengambilan data berlangsung. Pengolahan data tersebut berupa seabed tracking dan manager setting yang terdiri dari band-pass filtering (500 $\mathrm{kHz}$ pada low frequency dan $4000 \mathrm{kHz}$ high frequency), digital base gain (DBG), time-variable gain, zap filter, dan swell filter. hasil processing yang didapatkan berupa nilai easting, northing, dan thickness yang selanjutnya dilakukan processing untuk mendapatkan water depth reflektor per lintasan.

\section{Metode Pemeruman Dasar Laut}

Pemeruman dasar laut dilakukan dengan menggunakan multibeam echo sounder yang memiliki beberapa kelebihan daripada pada Single Beam echo sounder, yaitu multibeam menyediakan data yang sangat baik dalam cakupan area penelitian dan mampu menyimpulkan cross track bathymetry sebagai koreksi dalam membuat kelerengan dasar perairan sepanjang arah kapal melintas. Penelitian ini menggunakan alat multibeam echosounder yang dipasang di lambung kapal yang mentrasmisikan gelombang suara ke dasar perairan serta dipantulkan kembali oleh sedimen dasar perairan dan diterima oleh receiver (Penrose et al., 2005).

\section{Metode Interpretasi Refleksi Seismik}

Menurut Hasanudin (2005) bahwa penentuan interpretasi refleksi seismik terdiri dari pemetaan struktur geologi, analisi sekuen seismik, dan analisis fasies seismik. Namun, dalam penelitian ini interpretasi yang dilakukan untuk mengetahui batas-batas sekuen reflektor seismik, menentukan sekuen pengendapan dalam waktu, dan menganalisi terjadinya erosi yang dapat dilihat dari perubahan muka air laut. Tidak hanya waktu sekuen sendimentasi yang diperoleh namun juga memungkinkan untuk mengambil kesimpulan yang dapat menggambarkan tentang lingkungan pengendapannya.

\section{HASIL DAN PEMBAHASAN}

Rekaman sub-bottom profiler pada area muara sungai dengan lintasan 5M14 (Gambar 2a) merupakan lintasan yang berarah sejajar pantai dari mulut sungai ke arah barat menuju timur pada bagian dalam muara sungai, lintasan 5M13 (Gambar 2b) merupakan lintasan yang berarah sejajar pantai dan berada bersebalahan dengan lintasan 5M14 dari mulut sungai ke arah barat menuju timur pada bagian dalam muara sungai, dan lintasan 5M7 (Gambar 2c) merupakan lintasan yang berarah sejajar pantai dari mulut sungai ke arah barat menuju timur yang berbatasan dengan lepas pantai. Ketiga penampang seismik muara sungai tersebut mampu mewakili karakteristik dari lokasi penelitian di muara sungai yang terdiri dari 33 lintasan.

Interpretasi rekaman seismik berdasarkan pola reflektor tegas dan menerus dipisahkan berdasarkan pola reflektor yang selaras, reflektor ketidakselarasan, dan reflektor tegas. Rekaman seismik muara sungai di Perairan Sumbawa, Nusa Tenggara Barat memperlihatkan lapisan yang dibedakan menjadi 7 lapisan utama, yaitu:

1. Lapisan pertama merupakan lapisan teratas yang menandakan bahwa lapisan ini paling muda dari lapisan yang lainnya atau berumur recent yang tersusun atas coarse aluvial. Lapisan ini memiliki karakter konfigurasi internal reflektor seismik sub-parallel dan parallel yang 
menandakan terjadinya pengendapan seragam dengan fraksi berukuran sangat halus, yaitu clay.

(a).

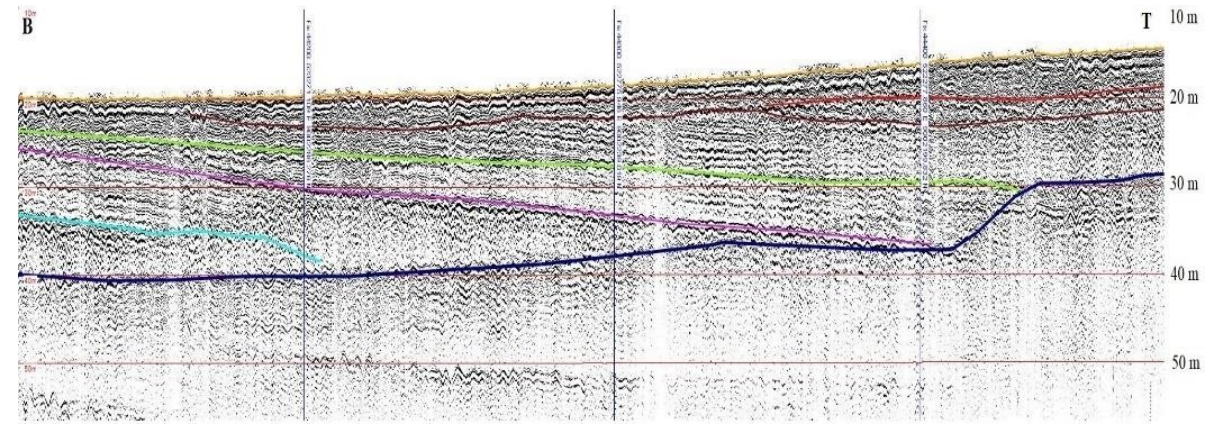

(b).

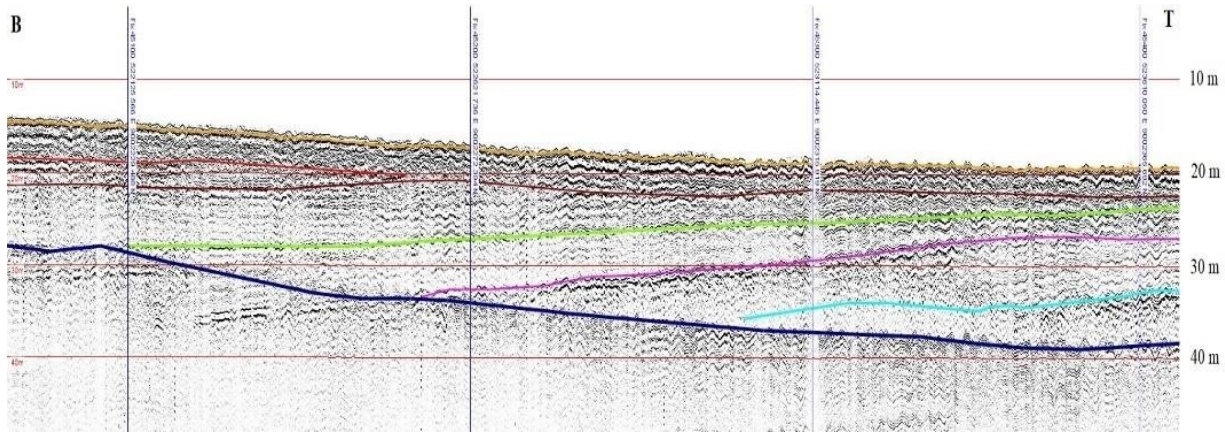

(c).

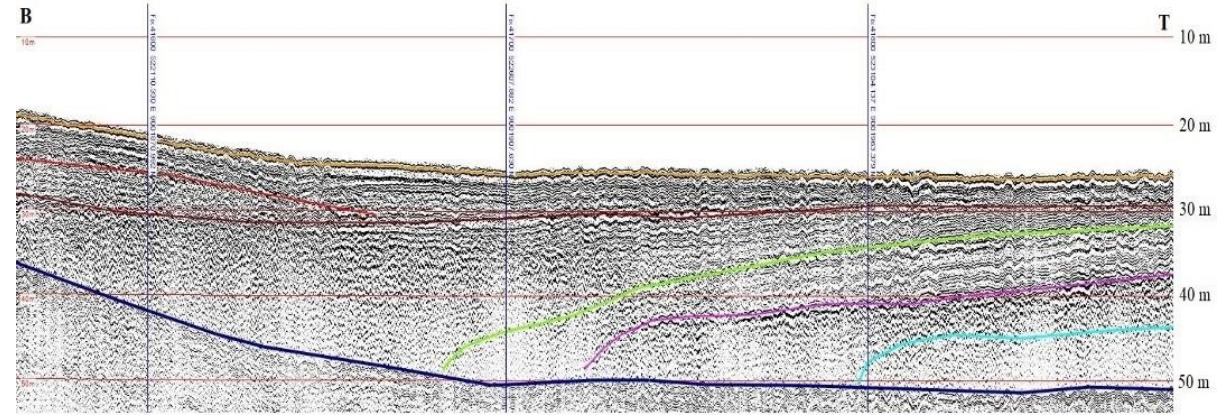

Gambar 2. Rekaman seismik muara sungai pada (a) lintasan 5M14, (b) lintasan 5M13, dan (c) lintasan 5M07

2. Lapisan kedua merupakan lapisan yang terletak di bawah lapisan pertama. Lapisan ini memiliki karakter konfigurasi internal reflektor seismik parallel simple stratified dan chaotic yang mencirikan lapisan sedimen tersusun dari fraksi butiran halus hingga sedang seperti lempung dan pasir halus.

3. Lapisan ketiga memiliki karakter konfigurasi internal reflektor seismik parallel lamination dan chaotic yang memincirikan lapisan sedimen berbutir sedang sampai dengan kasar seperti pasir berbutir sedang sedangakan chaotic merupak sedimen dengan pembentuk dari fraksi berukuran sedang dan terlihat membulat pada penampang seismik yang diperkirakan sebagai sedimen kompak

4. Lapisan keempat ini memiliki karakter konfigurasi internal reflektor seismik paralle lamination, chaotic, dan masking sand yang mencirikan sedimen pembentuk atas fraksi butiran berukuran sedang sampai dengan halus. Pola sekuen seismic parallel lamination semakin ke arah timur lebih mendominasi sedangkan semakin ke arah barat pola sekuen seismik chaotic dan masking sand lebih terlihat di penampang seismik yang mencirikan tersusun dari batuan keras dan pasir. 
5. Lapisan kelima merupakan lapisan sedimen yang terletak di bawah lapisan keempat. Lapisan ini memiliki karakter konfigurasi internal reflektor seismik sub-parallel dan chaotic. pola sekeun seismik sub-parallel ini mencirikan sedimen tersusun atas butiran halus sampai sedang. Pola sekuen seismik chaotic yang mencirikan lapisan ini adalah tersusun atas fraksi berukuran sedang dan dicirikan sebagai sedimen kompak.

6. Lapisan keenam ini memiliki karakter konfigurasi internal reflektor seismik masking sand. Pola yang dihasilkan mencirikan tingkat porositas sedimen pada lapisan ini tinggi sehingga terlihat transparan yang tersusun atas butiran halus seperti pasir akibat tidak mampunya gelombang seismik menembus lapisan ini.

7. Lapisan ketujuh merupakan lapisan sedimen yang terletak di bawah lapisan keenam. Karakter konfigurasi internal reflektor seismik parallel sampai sub-parallel dengan hasil rekaman yang sangat kuat yang mencirikan bahwa lapisan paling bawah merupakan lapisan keras. Lapisan ini merupakan lapisan paling dasar yang menandakan lapisan ini merupakan lapisan dengan umur paling tua dan tersusun atas sedimen yang keras yang terlihat dari pantulan seismik yang tegas dan kuat.

Rekaman sub-bottom profiler di lepas pantai pada dengan lintasan 4M07 (Gambar 3a) merupakan lintasan berarah sejajar dengan pantai dari lepas pantai menuju lepas pantai dengan kedalam yang semakin berkurang serta arah perekaman dari barat menuju ke timur lepas pantai, lintasan 4M03 (Gambar 3b) merupakan lintasan berarah sejajar pantai yang berada di lepas pantai dengan kedalam rata-rata dan arah rekaman dari barat menuju timur lepas pantai, dan lintasan 4M01 (Gambar 3c) merupakan sejajar pantai yang berada di lepas pantai dengan kedalaman ratarata dan arah rekaman dari barat ke timur lepas pantai yang berdekatan dengan lintasan 4M03. Dengan ketiga penampang seismik lepas pantai tersebut mampu mewakili karakteristik dari lokasi penelitian di muara sungai yang terdiri dari 89 lintasan.

Interpretasi rekaman seismik berdasarkan pola reflektor tegas dan menerus dipisahkan berdasarkan pola reflektor yang selaras, reflektor ketidakselarasan, dan reflektor tegas memperlihatkan lapisan yang dibedakan menjadi 3 lapisan utama, yaitu:

1. Lapisan ini memiliki karakter konfigurasi internal reflektor seismik parallel lamination, chaotic, dan masking sand. Pola sekuen seismik parallel lamination dicirikan dengan bentuk lapisan yang tersusun secara horizontal dan saling sejajar dengan lainnya dan pantulan rekaman seismik yang menipis dan menghilang. Pola sekuen seismik chaotic yang mencirikan sedimen pada lapisan ini tersusun atas fraksi berukuran sedang. Pola sekuen seismik masking sand dicirikan dengan pantulan seismik yang sangat transparan dan sinyal yang dihasilkan rendah. Pada lapisan ini tersusun atas fraksi sedang seperti pasir.

2. Lapisan kedua memiliki karakter konfigurasi internal reflektor seismik yang dimiliki lapisan ini adalah sub-parallel dan masking sand. Pola sekeun sub-parallel yang dicirikan dengan lapisan horizontal yang tidak beraturan dan rekaman seismik yang lemah dan terputus. Pola sekuen masking sand yang mencirikan lapisan ini tersusun atas fraksi butiran sedang seperti pasir.

3. Lapisan ketiga merupakan lapisan paling dasar dan berumur paling tua yang memiliki karakter konfigurasi internal reflektor seismik chaotic dan masking sand yang dicirikan dengan sinyal dari rekaman seismik sangat kuat dan tegas serta lapisan ini terbentuk dari butiran yang besar dan keras. Pada lapisan sedimen keras ini terlihat seperti cekungan yang terisi oleh lapisan sedimen dengan ukuran fraksi sedang hingga halus. 
(a).

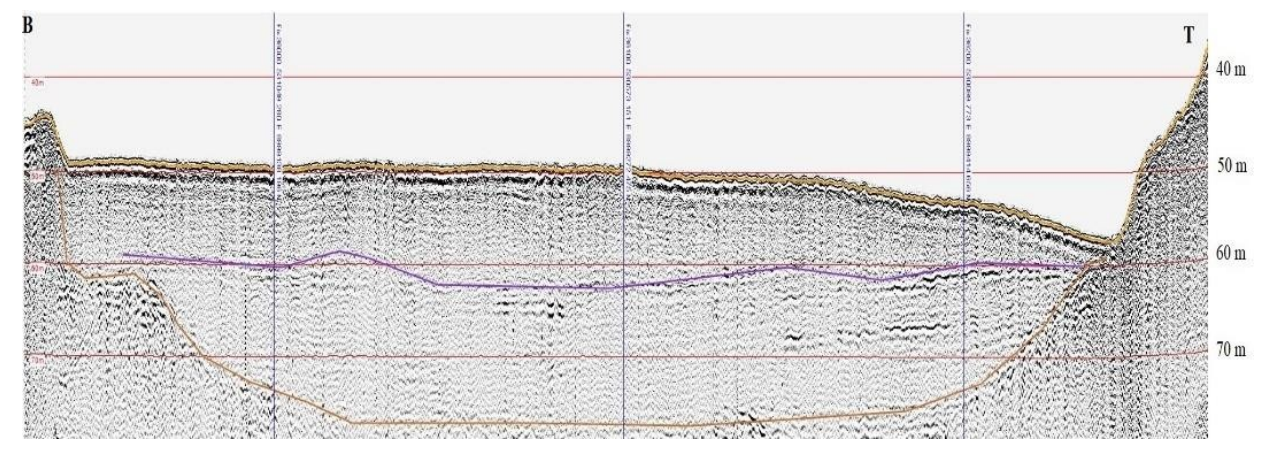

(b).

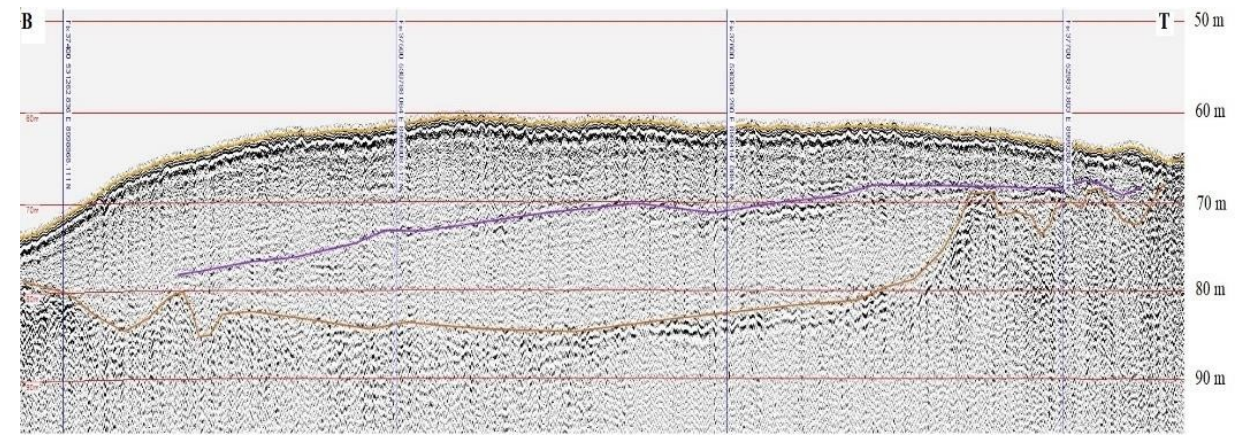

(c).

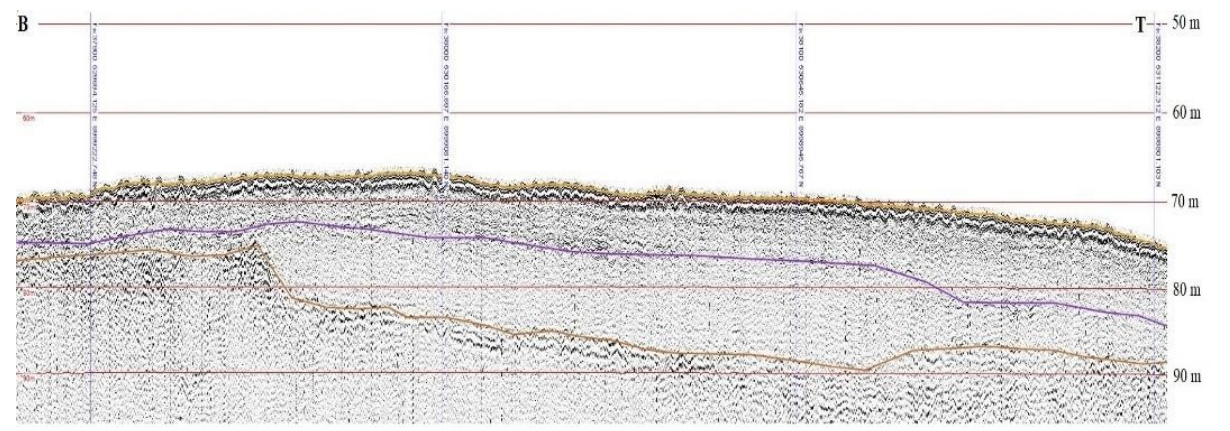

Gambar 3. Rekaman seismik lepas pantai pada (a) lintasan 4M07, (b) lintasan 4M07, dan (c) lintasan $4 \mathrm{M} 01$

Rekaman sub-bottom profiler pada area lepas pantai dengan lintasan 1M15 (Gambar 4a) merupakan berarah sejajar pantai yang berada di lepas pantai dengan kedalaman lebih dangkal serta arah rekaman dari arah barat ke arah timur lepas pantai, lintasan 1M03(Gambar 4b) merupakan lintasan berarah sejajar pantai dari lepas pantai dengan kedalaman yang lebih dalam serta arah rekaman dari arah barat ke arah timur lepas pantai, dan lintasan 1M01 (Gambar 4c) merupakan lintasan berarah sejajar pantai dari lepas pantai dengan kedalaman yang lebih dalam serta arah rekaman dari arah barat ke arah timur lepas pantai serta lintasan tersebut berdekatan dengan lintasan 1M03. Dengan ketiga penampang seismik lepas pantai tersebut mampu mewakili karakteristik dari lokasi penelitian di muara sungai yang terdiri dari 16 lintasan.

Interpretasi rekaman seismik berdasarkan pola reflektor tegas dan menerus dipisahkan berdasarkan pola reflektor yang selaras, reflektor ketidakselarasan, dan reflektor tegas memperlihatkan lapisan yang dibedakan menjadi 3 lapisan utama, yaitu:

1. Lapisan pertama dicirikan dengan karakter konfigurasi internal reflektor seismik masking sand dengan sinyal rekaman seismik yang tidak bisa menembus lapisan ini karena tingkat porositas yang tinggi lapisan sedimen ini tersusun dari fraksi butiran sedang seperti pasir dan sinyal yang transparan akibat dari kemampuan sedimen yang tidak mampu menyerap gelombang akustik. 
2. Lapisan kedua dengan karakter internal reflektor sub-parallel dan chaotic. Lapisan ini terususn atas lapisan keras terlihat dari pantulan seismik yang kuat pada bagian lapisan atasnya. Lapisan ini terdapat

lapisan sedimen keras yang terangkat ke atas sehingga terjadi transport sedimen dibagian barat sisi sedimen keras dan bagian timur mengalami penebalan lapisan.

(a).

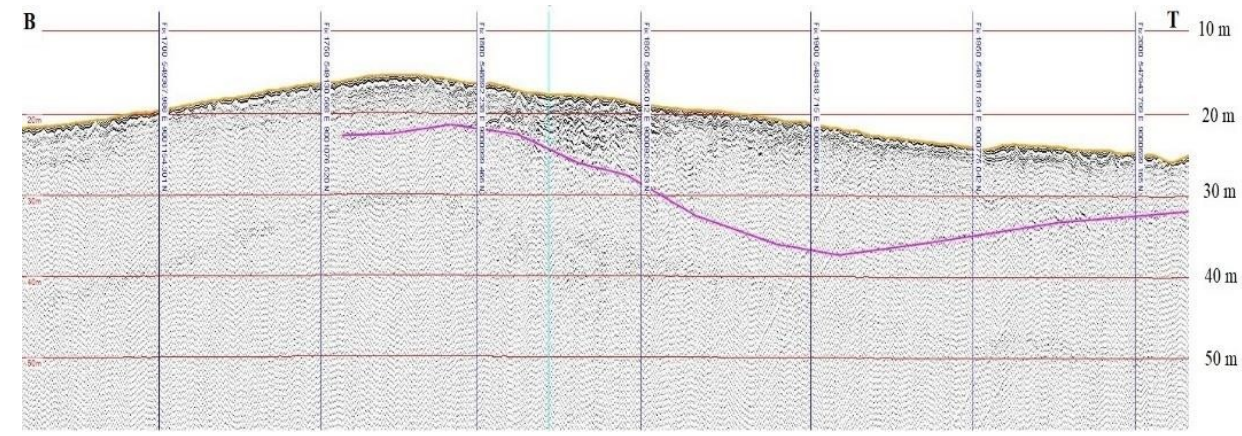

(b).

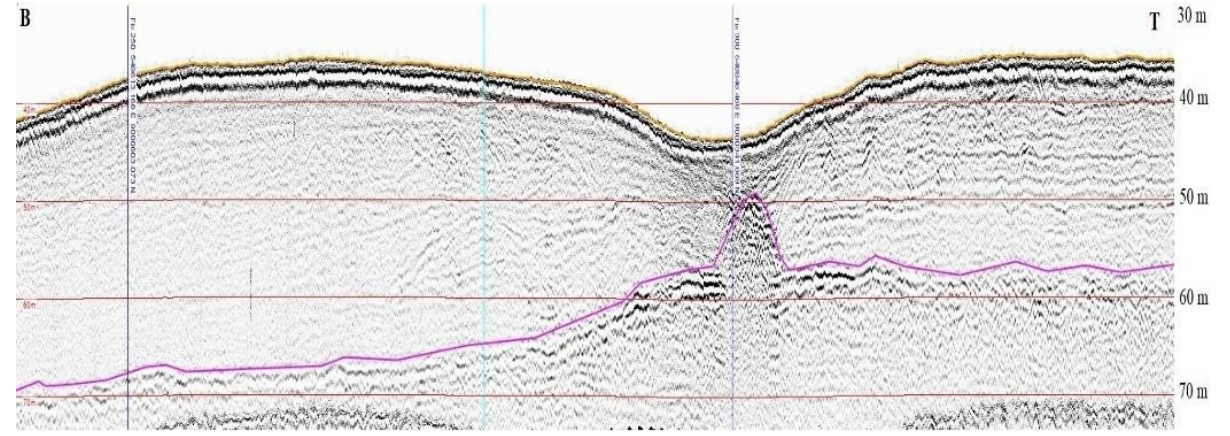

(c).

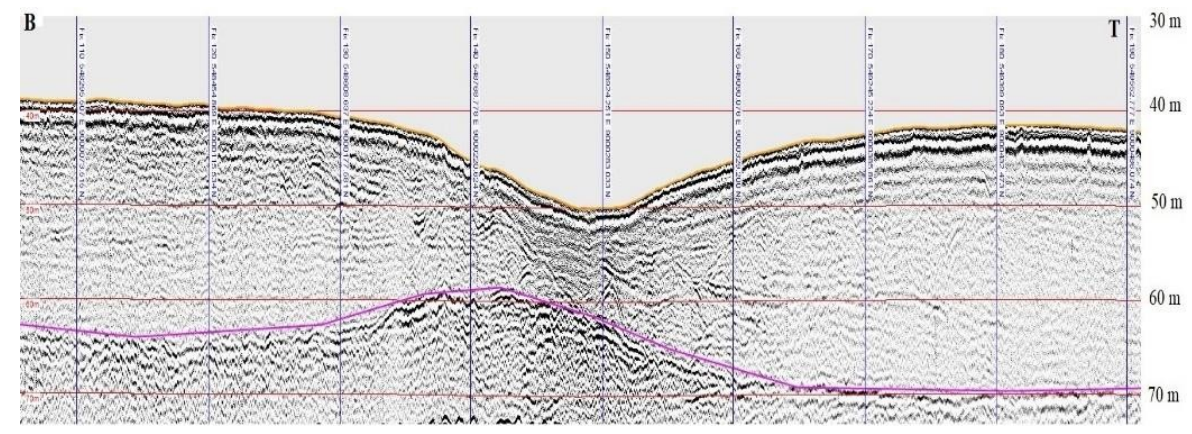

Gambar 4. Rekaman seismik lepas pantai pada (a) lintasan 1M15, (b) lintasan 1M0, dan (c) lintasan

1M01 Pola internal reflektor sub-parallel dan parallel ditemukan pada lapisan pertama muara sungai muara

sungai di mana pola tersebut diendapkan pada lingkungan berenergi rendah atau partikel sedimen mengalami depresi hingga menghalus ke arah bawah. Menurut Raharjo et al. (2019) pola internal reflektor sub-parallel dan parallel merupakan transportasi material yang berasal dari darat yang ditransportasi oleh aktifitas marine (longshore current dan tidal current) terbawa oleh aliran laminar. Aliran laminar bersifat steady yang berarti alirannya tetap mempunyai kecepatan relatif rendah dan gerak partikel sedimen yang terbawa fluida sejajar dengan garis-garis arus yang seolah bergerak sepanjang lintasan yang halus dan menunjukan bahwa saluran aliran air, debit alirannya 
tetap atau kecepatan alirannya tidak berubah menurut waktu (Simanjuntak et al., 2017).

Pola internal reflektor parallel lamination dan masking sand ditemukan pada lapisan pertama lepas pantai. Pola parallel lamination terbentuk akibat proses pengendapan secara perlahan butir per butir yang dipengaruhi oleh suspense dan pengendapan yang berganti-ganti dengan energi pengendapan yang rendah. Sedangkan pola internal reflektor masking sand dicirikan dengan pengendapan dengan arus yang tinggi untuk mempu membawa ukuran butir yang besar. Pola internal reflektor tersebut dapat terbentuk akibat adanya aliran turbulen. Menurut Simanjuntak et al., (2017) aliran turbulen merupakan kecepatan arus yang relatif besar, lintasan gerak partikel saling tidak teratur, dan panjang aliran yang besar.

Menurut Nicholas (2009) bahwa terdepositnya material sedimen dengan berbagai ukuran terangkut oleh aliran fluida memiliki mekanisme pergerakan partikel sedimen berupa gerakan rolling yang bersentuhan dengan dasar perairan, gerakan saltasi serangkain lompatan yang tidak bersentuhan dan kembali bersentuhan dengan dasar perairan, dan gerakan suspensi menghasilkan gerakan ke atas untuk menjaga partikel bergerak lebih atau kurang secara terus menerus. Ketiga mekanisme tersebut terjadi di muara sungai dan lepas pantai, di mana dengan arus yang rendah di muara sungai partikel halus seperti silt dan clay akan tersuspensi sedangkan partikel dengan ukuran yang lebih besar seperti pasir akan bergerak secara rolling dan beberapa mengalami saltasi. Sedangkan yang terjadi di lepas pantai akibat arus lebih tinggi partikel berupa silt dan pasir akan mengalami suspensi, partikel granules dan fine pebbles bergerak secara rotasi, dan partikel ukuran besar seperti material kasar bergerak rolling. Selain, besar dan kecilnya aliaran fluida mempengaruhi proses pengendapan juga disebabkan kecenderungan partikel untuk mengendap bergantung dari konsentrasi, ukuran butir, dan jenis partikel sedimen. Di mana terlihat pada hasil rekaman seismik lepas pantai pada bagian barat ditemukan 2 lapisan sedangkan bagian timur hanya 1 lapisan yang tebal akibat dari ukuran partikel lebih besar, konsentrasi partikel rendah, dan densitas partikel yang semakin besar pada bagian barat lepas pantai dan sebaliknya pada bagian timur lepas pantai ukuran partikel mengecil, konsentrasi partikel tinggi, dan densitas partikel rendah.

Proses sedimentasi yang terjadi di muara sungai dan lepas pantai memiliki perbedaan diantaranya adalah muara sungai (Gambar 2) memiliki sedimen penyusun atas 7 lapisan dan lapisan teratas didominasi oleh clay yang menandakan lokasi muara sungai pada penelitian ini memiliki aktivitas sedimentasi yang lebih tinggi dibandingankan transportasi sedimen sedangkan kedua lokasi lepas pantai (Gambar 3 dan 4) memiliki sedimen penyusun atas 3 lapisan dan 2 lapisan, lapisan teratas didominasi oleh pasir yang tebal akibat dari berbatasan dengan Samudera Hindia sehingga akhir transportasi sedimen yang membawa pasir lebih banyak ditemukan di lepas pantai sebagai penyusun lapisan teratas.

Bentuk morfologi dasar perairan muara sungai terlihat semakin curam dengan menjauhnya hilir muara sungai terhadap perbatasan mulut muara sungai dengan lepas pantai (Gambar 5). Bagian arah utara muara sungai memiliki kedalaman yang lebih dangkal pada -5 meter karena berada pada hilir muara sungai sedangkan kedalaman akan semakin curam ke bagian selatan dengan kedalaman 20 meter sampai dengan -50 meter karena berbatasan dengan lepas pantai. Bentuk morfologi muara sungai yang lebih berarturan dan semakin curam ke arah selatan maka menyebabkan kecepatan arus pada bagian mulut muara sungai lebih tinggi dibandingkan dengan kecepatan arus pada bagian hilir muara sungai. 


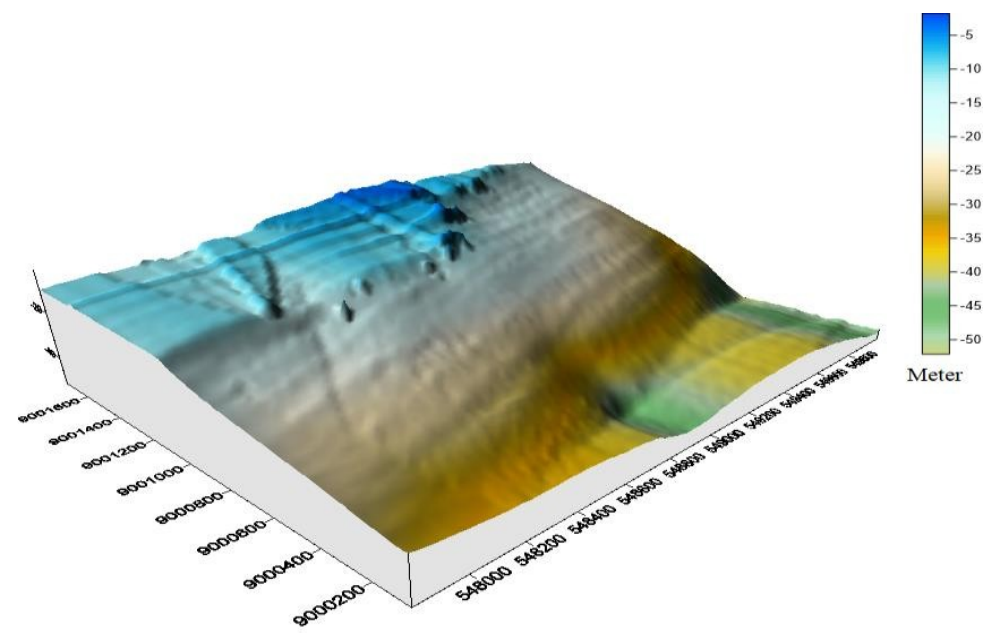

Gambar 5. Morfologi dasar perairan di muara sungai

Kedalaman morfologi dasar perairan lepas pantai bagian barat terlihat bahwa pada bagian arah utara memiliki kedalaman lebih dangkal -10 meter sampai dengan -30 meter, pada bagian selatan kedalaman dasar perairan lepas pantai memiliki kedalaman -50 meter sampai dengan -90 meter, dan pada bagian timur-tenggara kedalaman morfologi dasar perairan -110 meter sampai dengan -210 meter. Morfologi lokasi ini tidak beraturan dengan terdapatnya bagian batuan keras yang menonjol ke atas permukaan dasar perairan serta bentuk morfologi dasar perairan yang cenderung sangat curam. Hal tersebut menyebabkan berpengaruhnya kecepatan arus yang lebih tinggi pada bagian timur, tenggara, dan selatan karena pergerakan arus yang menabrak bagian batuan yang keras dengan kedalaman yang curam.

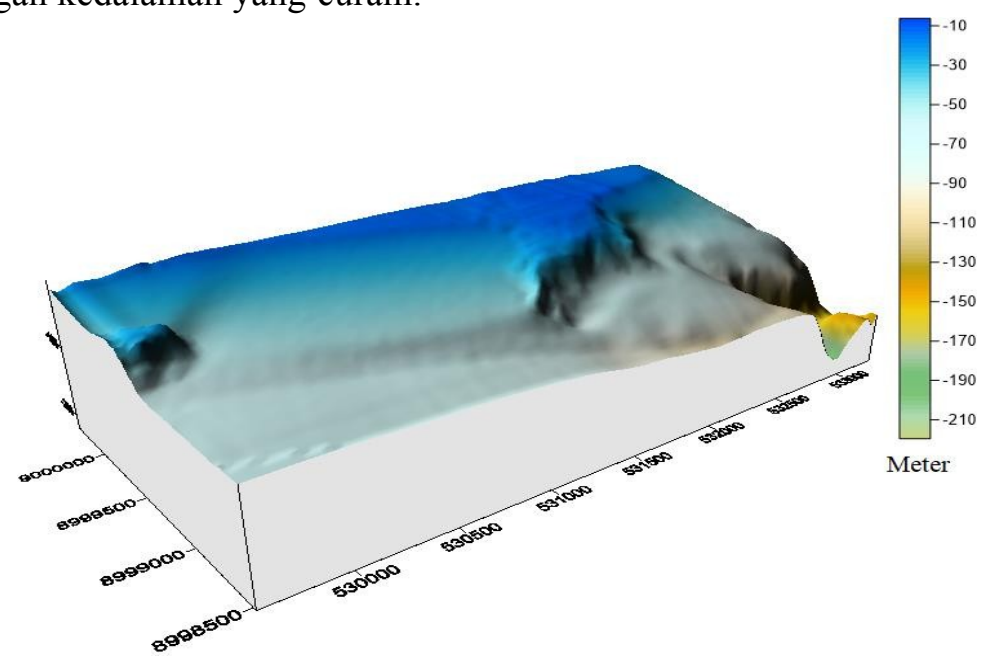

Gambar 6. Morfologi dasar perairan di lepas pantai

Morfologi dasar perairan lepas pantai zona di bagian timur menunjukan bahwa bagian utara memiliki kedalaman -15 meter sampai dengan -20 meter, pada bagian timur, tenggara dan selatan terjadi kecuraman bentuk morfologi dengan kedalaman -30 meter sampai dengan -50 meter. Berdasarkan kedalaman dan bentuk morfologi yang teratur pada bagian utara dan bentuk yang tidak teratur pada bagian tenggara dan selatan akan mempengaruhi kecepatan arus yang lebih tinggi pada bagian tenggara dan selatan dibandingkan bagian utara. 


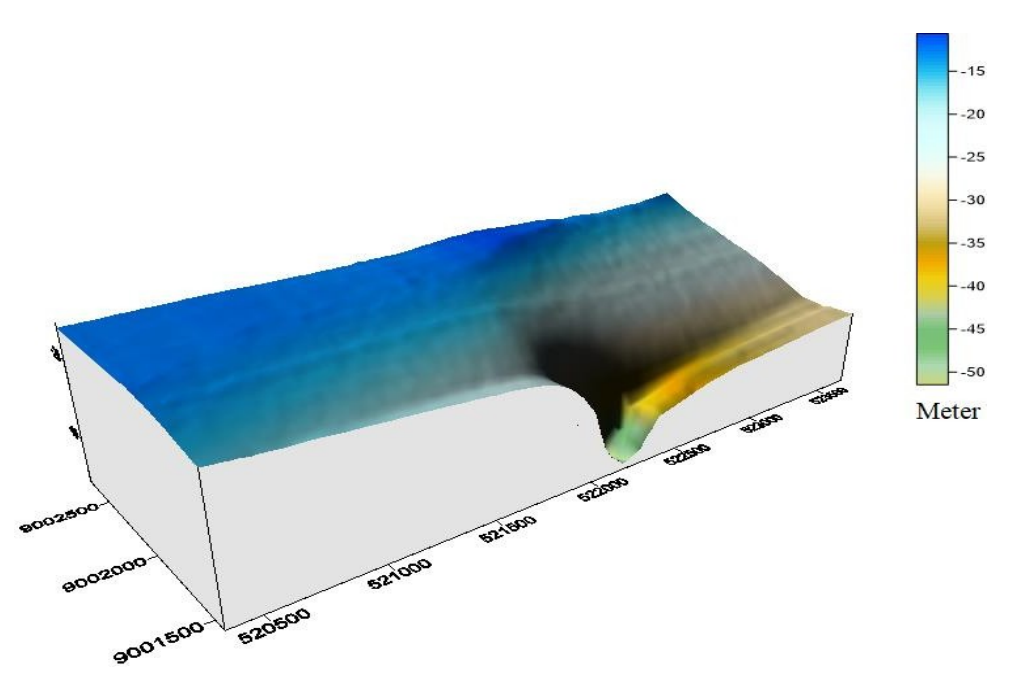

Gambar 7. Morfologi dasar perairan di lepas pantai

\section{KESIMPULAN}

Berdasarkan hasil peneltian yang dilakukan di Perairan Sumbawa, Nusa Tenggara Barat dapat disimpulkan bahwa:

1. Berdasarkan profil 2 dimensi penampang seismik sub-bottom profiler ditemukan 7 lapisan sedimen dasar penyusun muara sungai dan pola internal konfigurasi seismik tersebut, yaitu: subparallel, parallel simple stratified, chaotic, parallel lamination, dan masking sand, sub-parallel dan parallel sampai sub-parallel. Pada area lepas pantai ditemukan 2 lapisan sampai 3 lapisan sedimen dasar penyusun dengan pola internal konfigurasi seismik tersebut, yaitu: parallel lamination, chaotic, masking sand, dan sub-parallel.

2. Pola internal reflektor sub-parallel dan parallel pada muara sungai terbentuk akibat adanya transportasi material yang berasal dari darat oleh aktifitas marine (longshore current dan tidal current) terbawa oleh aliran laminar dengan kecepatan relatif rendah ketika arus pasang surut yang terendapkan secara bertahap. Sedangkan pada lepas pantai dijumpai pola internal reflektor parallel lamination yang terbentuk akibat proses pengendapan secara perlahan butir per butir yang dipengaruhi oleh suspense dan pengendapan energi rendah dan pola internal reflektor masking sand dicirikan dengan pengendapan dengan arus yang tinggi untuk mempu membawa ukuran butir yang besar terbentuk akibat adanya aliran turbulen.

\section{DAFTAR PUSTAKA}

Astjario, P. 2007. Indikasi Struktur Sesar Dan Lipatan Bawah Permukaan Dasar Laut Perairan Tuban, Jawa Timur. Jurnal Geologi Dan Sumberdaya Mineral. 17(2):109-111.

Boggs Jr, S., 2014. Principles Of Sedimentology And Stratigraphy. Pearson Education. United States Of America : Merrill Publishing Comapany.

Nichols, G., 2009. Sedimentology and stratigraphy. John Wiley \& Sons. United Kingdom : WileyBlackwell.208

Penrose, J.D., Siwabessy, P.J.W., Gavrilov, A., Parnum, I., Hamilton, L.J., Bickers, A., Brooke, B., Ryan, D.A. And Kennedy, P., 2005. Acoustic Techniques For Seabed Classification. Cooperative Research Centre For Coastal Zone Estuary And Waterway Management, Technical Report. $71-75$.

Prihantono, J., Hasanudin, M., Pryambodo, D.G., Troa, R.A., Triarso, E., Dewi, L.C. and Dillenia, I., 2016. Estimasi Ketebalan Pasir Laut di Perairan Utara Kabupaten Serang-Banten Menggunakan Sub Bottom Profiler. Jurnal Segara, 12(3), pp.149-157.

Rahili, N.R. and Cahyono, B.K., 2019. 3D Modeling and Volume Estimation of Riverbed Layers 
Based on Sub Bottom Profiler Measurement Data. JGISE: Journal of Geospatial Information Science and Engineering. 2(1):114.

Solihuddin, T., Sari, E.M. and Kusumah, G., 2011. Prediksi Laju Sedimentasi di Perairan Pemangkat. Sambas Kalimantan Barat menggunakan Metode Pemodelan, Buletin Geologi Tata Lingkungan. 21(3):123.

Raharjo, P., Saputra, M.D., Latuputty, G., Geurhaneu, N.Y. and Ilahude, D. 2019. Ketebalan Endapan Sedimen Pasir Laut Berdasarkan Data Seismik Dangkal Saluran Tunggal Di Perairan Takalar, Selat Makassar. Jurnal Geologi Kelautan. 17(1):67.

Simanjuntak, H.F.P., Manik, P. and Santosa, A.W.B. 2017. Analisa Pengaruh Panjang, Letak dan Geometri Lunas Bilga Terhadap Arah dan Kecepatan Aliran (Wake) Pada Kapal Ikan Tradisioal (Studi Kasus Kapal Tipe Kragan). Jurnal Teknik Perkapalan, 5(1):346.

Hasanudin, M., 2005. Teknologi Seismik Refleksi Untuk Eksplorasi Minyak Dan Gas Bumi. Oseana. 30:(4):8- 9 . 